\title{
Weather Derivatives: A New Class of Financial Instruments *
}

\author{
Melanie Cao \\ Schulich School of Business \\ York University \\ Toronto, Ontario, Canada \\ M3J 1P3 \\ mcao@schulich.yorku.ca
}

\section{Anlong $\mathrm{Li}$}

XL Weather \& Energy Inc.

100 First Stamford Place

Suite 360

Stamford, CT 06902

ALi@XLWE.com

\section{J ason Wei}

Joseph L. Rotman School of Management

University of Toronto

Toronto, Ontario, Canada

M5S 3E6

wei@mgmt.utoronto.ca

J anuary, 2004

\footnotetext{
* Cao and Wei gratefully acknowledge the financial support from the Social Sciences and Humanities Research Council of Canada. The views expressed here are solely the authors' and are not those of the XL Weather \& Energy Inc..
} 


\section{Introduction}

The history of weather derivatives dates back to the mid 90's, when deregulation of the energy and utility industries started in the U.S.. Faced with growing competition and uncertainty in demand, energy and utility companies sought for effective hedging tools to stabilize earnings. As monopolies gave way to competitive wholesale markets, hedging price alone was no longer adequate since the volumetric risk also came into play.

In the deregulated environment, energy merchants quickly realized that weather conditions were the main source of revenue uncertainties. Weather affects both short-term demand and long-term supply of energy. For instance, as shown in Figure 1, the electricity load depends heavily on the temperature level. Similarly in Figure 2, regressing the monthly delivery of natural gas against the monthly average temperature for the state of Illinois, we obtain an $R^{2}$ of 0.9416 . Therefore, short-term demand of power and energy is largely dictated by weather conditions. A particular weather pattern (e.g., a strong global warming trend) can also affect the long-term supply as energy producers re-adjust their production levels.

The close association between the short-term demand for energy and weather conditions created a natural impetus for the development of weather derivatives. Although deals were struck as early as 1996, the first publicized deal was signed in 1997 between Koch Energy and Enron (now a defunct company) on a temperature index for Milwaukee, Wisconsin for the winter of 1997-1998. Since then, additional transactions were executed in different regions among many more players.

As shown in Figure 3, the number of contracts (per year) in over-the-counter (OTC) markets has been increasing steadily. ${ }^{1}$ For the year 2001 alone, almost 4,000 contracts were struck. The

\footnotetext{
${ }^{1}$ Figures 3 through 7 are based on surveys conducted by PricewaterhouseCoopers (http://www.pwcglobal.com) on behalf of Weather Risk Management Assocaition (http://www.wrma.org).
} 
notional value of the market grew in tandem with the volume, as shown in Figure 4. By 2001, the overall market size had grown to more than $\$ 4$ billion. As far as contract type is concerned, Figure 5 shows that, about $60 \%$ of the deals were on heating degree days (HDDs) and about $30 \%$ on cooling degree days (CDDs). For any given year, more than $80 \%$ of the contracts were on temperature variables. Moving on to notional value by contract type, we see in Figure 6 that temperature derivatives again dominated the market, accounting for more than $90 \%$ of the total value in any given year. Finally, the geographic distribution of the weather derivatives market is by no means uniform. Figure 7 indicates that the vast majority of the contracts were for the North American region, with Europe and Asia trailing behind at a decent growth rate. Within North America, the east and Midwest regions saw most of the deals, mainly due to the larger temperature variations in these regions.

The rapid growth of the OTC markets propelled the growth of organized markets. In September 1999, the CME began listing futures and options on temperature indices of 10 U.S. cities (Atlanta, Chicago, Cincinnati, New York, Dallas, Philadelphia, Portland, Tucson, Des Moines and Las Vegas). The 10 cities were chosen based on population, the variability in their seasonal temperatures and the activities seen in OTC markets. Dealers specializing in HDD / CDD swaps and options need a liquid market to lay off their risk, and the standardized CME contracts are the perfect vehicle for this purpose. The active OTC markets and the appointment of a market maker ${ }^{2}$ helped to boost the trading volume on the CME. The total number of contracts traded was 4,165 in 2002 and 14,234 in 2003.

Weather conditions affect not only the energy and utility sectors, but also many other sectors such as agriculture, retail, entertainment, and tourism. In fact, nearly twenty percent of the U.S. economy is directly affected by weather (see Challis [1999] and Hanley [1999]). As long as an

\footnotetext{
${ }^{2}$ In May 2002, Wolverine Trading, L.P. was named as the Lead Market Maker in CME's weather futures contracts. Wolverine posts continuous bids and offers each day to ensure the liquidity of the market.
} 
enterprise's fortune is subject to the mercy of mother nature, weather risk will be a crucial part of the overall risk to manage. Weather derivatives therefore play an important role in the endeavour of integrated risk management.

Still unrecognized by the investment community is the broader role of weather derivatives in portfolio management. From the perspective of Markowitz mean-variance efficiency, as long as the market is not complete, a new asset class will always improve the risk-return trade-off. The relatively lower correlation between weather derivatives and conventional financial assets suggests that weather derivatives can be an excellent diversification vehicle.

In the remainder of the article, we first describe the main weather derivative products and their usage in managing various weather risks; we then provide an overview of the modelling and pricing issues; and finally, we demonstrate the role of weather derivatives in portfolio management.

\section{Product Descriptions}

Although deals have been struck on such underlying variables as temperature, rainfall, snowfall and humidity, the vast majority of contracts are on temperature. The two most popular contract variables are the heating degree day (HDD) and cooling degree day (CDD). A degree day measures how much a day's average temperature deviates from $65^{\circ} \mathrm{F}$ (or $18.33^{\circ} \mathrm{C}$ ), a level of indoor temperature deemed to be comfortable by the utility industry. It is assumed that for each degree below $65^{\circ} \mathrm{F}$, more energy is needed to heat the room and for each degree above $65^{\circ} \mathrm{F}$, more energy is needed to power the air conditioners. Therefore HDD / CDD measure the coldness / warmth of the temperature. Precisely speaking, daily $\operatorname{HDD}=\max \left[0,65^{\circ} \mathrm{F}-\right.$ daily average temperature $]$ and daily $\mathrm{CDD}=\max \left[0\right.$, daily average temperature $\left.-65^{\circ} \mathrm{F}\right]$, where "daily average temperature" is the average of the maximum and minimum temperatures of the day.

Most contracts are written on the accumulation of HDDs or CDDs over a calendar month or a 
season so that one contract can hedge against revenue fluctuations over the concerned period. For instance, at the CME, all contracts are for monthly cumulative HDDs or CDDs.

In some cases, "energy degree day" (EDD) is used in lieu of HDD or CDD. EDDs are the absolute deviation from a benchmark temperature which can be different from $65^{\circ} \mathrm{F}$. When the benchmark temperature is $65^{\circ} \mathrm{F}$, EDDs are simply the sum of HDDs and CDDs. EDDs can help manage the temperature risk not just for a season but for the whole year. Table 1 contains an example of calculating the daily and cumulative HDDs, CDDs and EDDs.

Broadly speaking, there are three types of temperature derivatives: futures / forward, swaps, and options. Besides the underlying variable HDD or CDD, a contract must specify such basic elements as the accumulation period, the index station which records temperatures used to construct the underlying variable, and the tick size, i.e., the dollar amount attached to each HDD or CDD. The following contains examples of HDD- and CDD-based forward and option contracts.

\begin{tabular}{|c|c|c|}
\hline & HDD Forward & CDD Put Option \\
\hline Current time & December 1, 2001 & $\overline{\text { January } 1,2002}$ \\
\hline Location & Phil. Int'l Airport, Philadelphia & Hartsfield Airport, Atlanta \\
\hline Long Position & ABC Bank & Air Conditioning Ltd. \\
\hline Short Position & Power Supply Ltd. & XYZ Bank \\
\hline $\begin{array}{l}\text { Accumulation } \\
\text { Period }\end{array}$ & February, 2002 & July, 2002 \\
\hline Tick Size & $\$ 4,000$ per HDD & $\$ 10,000$ per CDD \\
\hline Settlement Level & 850 HDDs & \\
\hline Strike Level & & 550 CDDs \\
\hline Actual Level & 650 HDDs & 510 CDDs \\
\hline $\begin{array}{l}\text { Payoffs at Maturity } \\
\text { (Long Position) }\end{array}$ & $(650-850) \times 4000=-\$ 800,000$ & $(550-510) \times 10000=\$ 400,000$ \\
\hline
\end{tabular}

In the HDD forward example, Power Supply Ltd. agreed to short the cumulative HDDs for the month of February using the Philadelphia International Airport as the index station. The settlement level was 850 HDDs. The tick size was set at $\$ 4,000$ per HDD, which measures the sensitivity of Power Supply's revenue with respect to changes in the HDD level. With a realization 
of 650 HDDs, ABC Bank paid Power Supply Ltd. \$800,000 to settle the contract.

The CDD put option works in a similar fashion. A cap or maximum payoff is typically specified for an option contract. For instance, the payoff function for a CDD put option with a cap would be specified as, $\min [$ cap, tick $\times \max (0$, strike $-C D D)]$. In our example, had a cap of $\$ 350,000$ been specified, the settlement payoff would have been $\$ 350,000$.

\section{Illustrations of Weather Risk M anagement}

As any other derivative securities, weather derivatives serve the ultimate purpose of risk transfer. Power and utility companies are interested in smoothing their earnings by engaging in price and volumetric hedges. Insurance companies, power / energy brokers, and brokerage firms are in a position to act as counterparties thanks to their ability to effectively pool the weather risk and eventually lay it off in the organized market such as the CME. Of course, they earn a fee or a mark-up in the process. Below, we show two fictitious examples of using weather derivatives to manage weather risk.

Example 1: Natural Gas / Electricity Companies. The high correlation between power / energy consumptions and temperatures, as evident in Figures 1 and 2, means that the volumetric risk can be effectively hedged with weather derivatives. Let us examine the following.

Situation: Windy Powers Inc. is a power company supplying electricity to a community in the Chicago area. It is now December 1, 2003, and the company is making plans to hedge the weather risk for the period of January 1, 2004 through March 31, 2004. The company has performed statistical analyses and found the following: the average electricity price for the first three months of the year is around $\$ 25$ / MWh and the total sales volume is about $800,000 \mathrm{MWh}$; the average threemonth cumulative HDD is around 3,000 HDDs; for each unit decrease in HDDs the total revenue drops by about $\$ 8,000$. The company would like to neutralize the volumetric risk completely. 
Solution: Windy Powers Inc. enters into a forward contract with KDV Corp. (an energy broker) to short the three-month cumulative HDDs with a settlement level of 3,000 HDDs. The chosen station is the O'Hara Airport. The tick size is the revenue sensitivity, i.e., $\$ 8,000$. Since the settlement level is the historical average, the contract has an initial value of zero. When the contract is settled on March 31, 2004, Windy Powers's revenue will be maintained at the desired level, regardless of the realized HDDs for the season, as shown below.

$\begin{array}{cccc}\text { Realized } & \text { Gross } & \text { Gain / Loss from } & \text { Net } \\ \text { HDDs } & \text { Revenue }(000 \mathrm{~s}) & \text { Contract }(000 \mathrm{~s}) & \text { Revenue }(000 \mathrm{~s}) \\ 3,400 & \$ 23,200 & -\$ 3,200 & \$ 20,000 \\ 3,200 & \$ 21,600 & -\$ 1,600 & \$ 20,000 \\ 3,000 & \$ 20,000 & \$ 0 & \$ 20,000 \\ 2,800 & \$ 18,400 & \$ 1,600 & \$ 20,000 \\ 2,600 & \$ 16,800 & \$ 3,200 & \$ 20,000\end{array}$

If Windy Power Ltd. wishes to eliminate the downside volumetric risk while retain the upside potential, it could purchase a put option on the three-month cumulative HDDs. The strike price should be set at 3,000 HDDs, and the tick size at $\$ 8,000$. Of course, the company will incur an up-front cost to acquire such an option.

Example 2: Entertainment, R estaurants and Bars. People tend to go out more when the weather is nice. While the long-run fortune of an entertainment establishment or a restaurant depends on many factors such as the state of the economy, management skills, and service quality, the short-run business level could depend heavily on weather conditions. This is especially so for bars and night clubs. The following is based on a deal reported by The Times (April 16, 2001). ${ }^{3}$

Situation: Timthy's is a chain of wine bars in London. Years of observations indicate that business tends to peak on Thursdays and Fridays when workers start to wind down for the week.

\footnotetext{
${ }^{3}$ T he Times reported that Corney \& Barrow, a chain of London wine bars struck a deal which allowed them to receive a payout of up to $\$ 15,000$ on every Thursday and Friday in the summer season when the temperature failed to reach $24^{\circ} \mathrm{C}$. Speedwell Weather Derivatives, a UK based weather consultancy and software company, helped perform the statistical anaylsis and arrange the deal.
} 
Additionally, it notices that the volume of customers drops precipitantly when the summer temperature is below a certain level. After a few years of tabulation of the daily temperature and customer volume, Timthy's concludes that $22^{\circ} \mathrm{C}$ seems to be the temperature threshold below which business starts to suffer. Compared with regular warmer days, cooler Thursdays or Fridays on average cost the chain about $\$ 10,000$ per day in revenues. It is now March 1, 2003 and the wine bar chain would like to hedge against unfavorable temperatures for the coming summer.

Solution: Timthy's strikes a deal with Exxanron (a dealer of weather derivatives) based on the temperature of "critical days" throughout the summer (from June 15, 2003 to September 15, 2003). The "critical days" are Thursday and Friday of each week. On each critical day, if the temperature fails to reach $22^{\circ} \mathrm{C}$, Exxanron will pay Timthy's $\$ 10,000$. To cover itself for extreme events (e.g., cooler than normal temperatures for the whole summer), Exxanron caps the total payout at \$150,000. To acquire the weather hedge, Timthy's pays Exxanron a one-time "insurance fee" of $\$ 20,000$. This fee is the fair value of the contract which is calculated through sophisticated meteorological analysis. In particular, it results from an overall estimate of the probability that the temperature will be below $22^{\circ} \mathrm{C}$ on each critical day. This probability is assessed to be around 10\%. Since there are 24 critical days in the period of June 15, 2003 to September 15, 2003, the total expected payoff is therefore $24 \times 10,000 \times 10 \%=\$ 24,000$. The actual fee is $\$ 4,000$ less, reflecting the cap of total payoff at $\$ 150,000$.

\section{Overview of Temperature M odeling and Derivatives Valuation}

The valuation of temperature derivatives has some unique features. To start with, the underlying is a meteorological variable rather than a traded asset. The conventional risk-neutral, arbitrage valuation does not apply. In addition, being a meteorological variable, temperature follows a predictable trend, especially over a longer horizon. The unique nature of the temperature variable 
brings about two important issues: accurate modeling of the underlying and the assessment of the market price of risk.

The academic literature only begins to make progress in valuing this new class of derivative securities (see, e.g., Cao and Wei [2003]). In the industry, regardless of the valuation methodologies, a mark-up is usually attached to the model price as a cushion for errors. From the modeling perspective, the existing valuation methods can be loosely classified into three categories: 1) insurance or actuarial valuation, 2) historical burn analysis, and 3) valuation based on dynamic models.

Insurance or A ctuarial M ethod. This method is widely used by insurance companies, and its backbone is statistical analysis based on historical data. A probabilistic assessment is attached to the insured event and a fair premium is calculated accordingly. In the case of weather derivatives, this method is less applicable for most contracts since the underlying variables (e.g., temperature) tend to follow a recurrent, predictable pattern. Nonetheless, if the contract is written on rare weather events such as extreme heat or coldness, then this method will be very useful. In fact, one may even argue that this is the only appropriate method in this case. For instance, using a diffusion process to model the temperature will be misguided if the main interest is in extreme events.

Historical Burn Analysis. This method is perhaps the simplest to implement, and as a result, is most prone to large pricing errors. In a nutshell, this method evaluates the contract against historical data and takes the average of realized payoffs as the fair value estimate (see Dischel [1999] for further discussions). The key assumption is that, the past always reflects the future on average. This is a strong requirement in most cases. To appreciate this point, we apply the historical burn analysis to call options written on the three-month (January, February and March) cumulative HDDs for Atlanta and New York. ${ }^{4}$ Table 2 contains the calculations. We first calculate the realized cumulative HDDs for each year, and then evaluate the option's payoff

\footnotetext{
${ }^{4}$ The historical daily temperatures are obtained from the National Climate Data Center.
} 
accordingly (the exercise prices are set at 1,500 and 2,500 for Atlanta and New York, respectively). These are reported in the four columns next to the first column. The last two columns show the option value estimates under different sample lengths. Take Atlanta as an example. When we use all 20 historical observations, the average payoff is 92.15 ; when the most recent 19 observations are used, the average payoff is 82.37 ; ....; when we use only the recent 10 observations, the fair value estimate is 22.50. Going back 10 years versus 20 years would lead to a difference of more than $300 \%$ in value estimates! Although the estimates for the option on New York's HDDs have a smaller dispersion, the highest estimate is still $70 \%$ higher than the lowest estimate.

It is not true that a longer time series will always enhance valuation accuracy. Although more data will cover more temperature variations, the future temperature behavior, which drives the derivative security's value, may be quite different from history. This is especially important when the derivative security's maturity is short. Ultimately, it boils down to a trade-off between statistical power and representativeness. The commonly accepted sample length in the industry appears to be between 20 and 30 years.

Similar to the insurance or actuarial method, historical burn analysis is incapable of accounting for the market price of risk associated with the temperature variable. These methods are only useful from the perspective of a single dealer. We need a dynamic and forward looking model to establish a unique market price which incorporates a risk premium.

Dynamic Valuation Models. In contrast to previous methods, a dynamic model directly simulates the future behavior of temperature as a continuous or discrete stochastic process. The continuous process usually takes the following mean-reversion form,

$$
d Y(t)=\beta[\theta(t)-Y(t)] d t+\sigma(t) d z(t)
$$

where $Y(t)$ is the current temperature, $\theta(t)$ is the deterministic long-run level of the temperature, $\beta$ is the speed at which the instantaneous temperature reverts to the long-run level $\theta(t), \sigma(t)$ is the 
volatility which is season-dependent, and $z(t)$ is a Wiener process which models the temperature's random innovations (see Dischel [1998] and Brody, Syroke and Zervos [2002] for similar specifications). The process in (4.1) needs to be discretized in order to estimate $\beta$ and the parameters imbedded in $\theta(t)$ and $\sigma(t)$. The functional forms for $\theta(t)$ and $\sigma(t)$ can be specified based on careful statistical analyses. Once the process in (4.1) is estimated, one can then value any contingent claim by taking expectation of the discounted future payoff.

The above continuous setup usually does not admit closed-form valuation formulas. Additionally, a risk-neutral valuation is imposed without any theoretical justification, and the market price of risk is rendered irrelevant. Moreover, the process in (4.1) can not reflect the persistent serial correlations typically present in daily temperatures.

With the above in mind, researchers (e.g., Cao and Wei [2000], Diebold and Campbell [2002], and Cao and Wei [2003]) have proposed discrete processes. In addition, Cao and Wei [2003] weave the temperature uncertainty and the economy's aggregate output into an equilibrium framework. Motivated by the significant influence of weather on the overall economy, Cao and Wei [2003] propose a serially correlated bivariate-process for the temperature and the aggregate output, and address the market price of weather risk therein.

The temperature process proposed by Cao and Wei [2003] possesses the following features, all of which are based on their careful study of the temperature behavior for U.S. cities: 1) the daily temperature has two components, the first being the seasonal pattern plus a global warming trend and the second being a random innovation, 2) the innovation is serially correlated, and 3) the standard deviation of the innovation is higher in the winter and lower in the summer, captured by a sine wave function. The aggregate output follows a mean-reverting process which is correlated with the current and past temperature innovations. The last building block is the representative agent's preference, which Cao and Wei [2003] specify as constant relative risk aversion (CRRA). 
Given the temperature risk embedded in the aggregate output, the risk aversion determines the risk premium via equilibrium valuations.

The market price of risk associated with the temperature variable is found to be significant in most cases. Risk premium can represent a significant portion of the derivative's value. Using the risk-free rate to discount the expected payoff will lead to a sizeable error. It is also found that the market price of risk affects option values much more than forward prices. This result is mainly due to the non-linearity in option's payoffs. Intuitively, the market price of risk tends to be integrated out in the linear payoffs of forward contracts.

In sum, there are several valuation methods for temperature derivatives. The ultimate choice depends on the trade-off between simplicity and accuracy.

\section{A sset Allocation and Weather Derivatives}

The role of weather derivatives in asset allocation and portfolio management is largely unexplored in the literature. Purely from a diversification perspective, this new class of financial instruments may indeed hold some potential. To gain some insight, we now examine the efficient frontiers consisting of the following asset classes: equity, fixed income, commodities, and temperature instruments.

Three indices are included in the equity class, namely, the regional indices for North America, Europe, and Pacific. The fixed income class is represented by the JP Morgan Bond Index. The asset class of commodities is represented by the Goldman Sachs Commodity Index which covers industrial metals, precious metals, live stocks, agriculture and energy. All of the above indices are retrieved from Datastream. For the weather investment class, we construct a hypothetical index using New York City's historical temperatures. The index is the 30-day lead daily EDD residual which is constructed by subtracting the historical average EDDs from that day's realized EDDs. For instance, if the historical average EDDs for January 1 is 27 and the realized EDDs for January 
1, 2001 and January 1, 2002 are 24.5 and 30.6 respectively, then the two residuals will be -2.5 and 3.6. To avoid negative index level (for the purpose of calculating returns) and to scale the variance of the return series, we add 1,000 to the EDD residual to arrive at the temperature index. The 30-day lead is used to rule out predictability. ${ }^{5}$ Finally, all the time series are for the period of January 1, 1991 to December 31, 2002 with daily frequency.

Table 3 presents the annualized means, standard deviations, and the correlation matrix for the six indices. The North American market fared the best in terms of annualized average returns (8.61\%), followed by the European market (4.80\%). The Pacific market saw an average loss of 2.23\%. It also exhibited the largest standard deviation. The bond index produced a modest gain $(1.26 \%)$, while both the commodity and the temperature indices experienced a minor loss $(-0.27 \%$ and $-0.02 \%)$. As for correlations, the equity indices exhibit relatively larger correlations among themselves. The highest correlation, 0.3815, is between the North American market and the European market. ${ }^{6}$ By and large, the correlation of temperature index with other indices is close to zero, suggesting potentials for diversification.

Figure 8 presents efficient frontiers constructed using the above data. To see how much each asset class can contribute to overall diversifications in addition to equities, we start with the three equity indices and add one index at a time. It is seen that adding the fixed-income asset class lowers the minimum variance substantially, and improves the risk-return trade off for the higher range of standard deviations. As a matter of fact, adding the commodity or temperature asset class to the three equity indices lead to similar results. Now, once the bond index is included, introducing the commodity index does not lead to noticeable improvements in risk-return tradeoffs. However, including the temperature index over and above all other indices does lead to a

\footnotetext{
${ }^{5}$ It is well known that the current technology can not produce reliable and accurate daily temperature forecasts beyond 10 days into the future.

${ }^{6}$ The correlation is higher if the indices are measured in local currencies. Here, the Europe and Pacific indices are measured in U.S. dollars since we take the perspective of a U.S. investor.
} 
visible improvement, especially in the higher range of the standard deviation. For instance, at a portfolio standard deviation of 0.3 , the expected return improves by about 40 basis points after adding the temperature index; the improvement is about 60 basis points for a standard deviation of 0.4. We can therefore conclude that weather derivatives, as an alternative class of financial instruments, do hold potential in asset allocation and portfolio management.

\section{Summary}

This article offers a brief survey of this emerging market. The structure and usage of various weather derivative products are surveyed, and the modeling and pricing issues are discussed. The literature on weather derivatives valuation is still in its infancy, and much more research needs to be done to accurately model weather variables. The article also demonstrates the role of weather derivatives in portfolio management. As an alternative class of financial instruments, weather derivatives can improve the risk-return trade-off in asset allocation decisions. 


\section{References}

[1] Brody, D.C., J. Syroke and M. Zervos, "Dynamic Pricing of Weather Derivatives", Quantitative Finance, 2 (2002), 189-198.

[2] Cao, M. and J. Wei, "Pricing the Weather", Risk, May (2000), 67-70.

[3] Cao, M. and J. Wei, "Weather Derivatives Valuation and Market Price of Weather Risk", J ournal of Futures Markets, 2003, forthcoming.

[4] Challis, S., "Bright Forecast for Profits", Reactions, June (1999).

[5] Diebold, F. X. and S. Campbell, "Weather Forecasting for Weather Derivatives", working paper (2002), University of Pennsylvania.

[6] Dischel, B., "Black-Scholes Won't Do", Risk, October (1998), 8-9.

[7] Dischel, B., "Shaping History", W eatherR isk (Special Report of Risk, 1999), 13-15.

[8] Hanley, M., "Hedging the Force of Nature", Risk Professional, 5 July/August (1999), 21-25.

[9] Locke, Jane, "A Cure for Power Price Spikes?", W eatherR isk (Special Report of Risk, October 1998), 4-5. 
$\underline{\text { Figure 1: Electricity Consumption Versus Temperature }}$

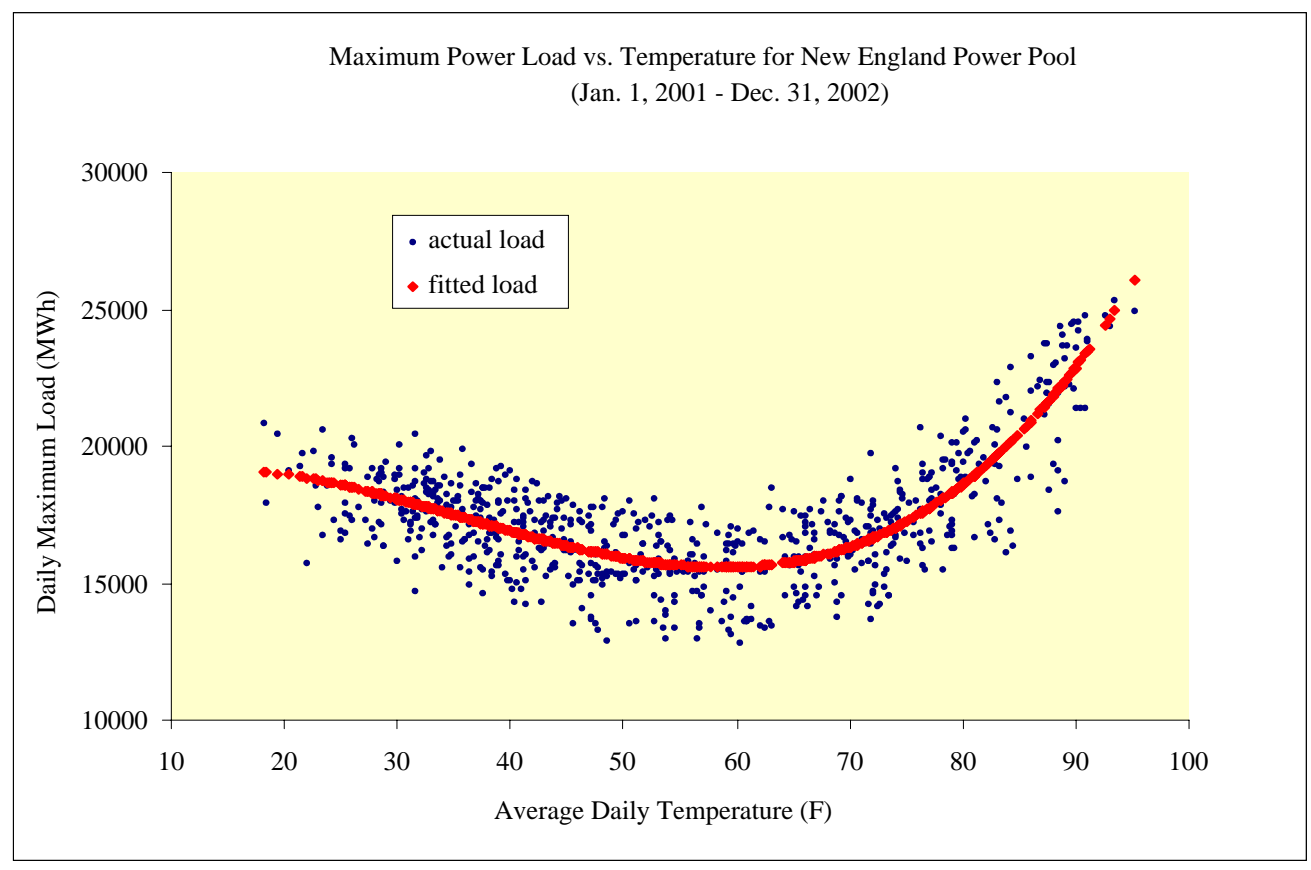

Figure 2: Natural Gas Consumption Versus Tempature

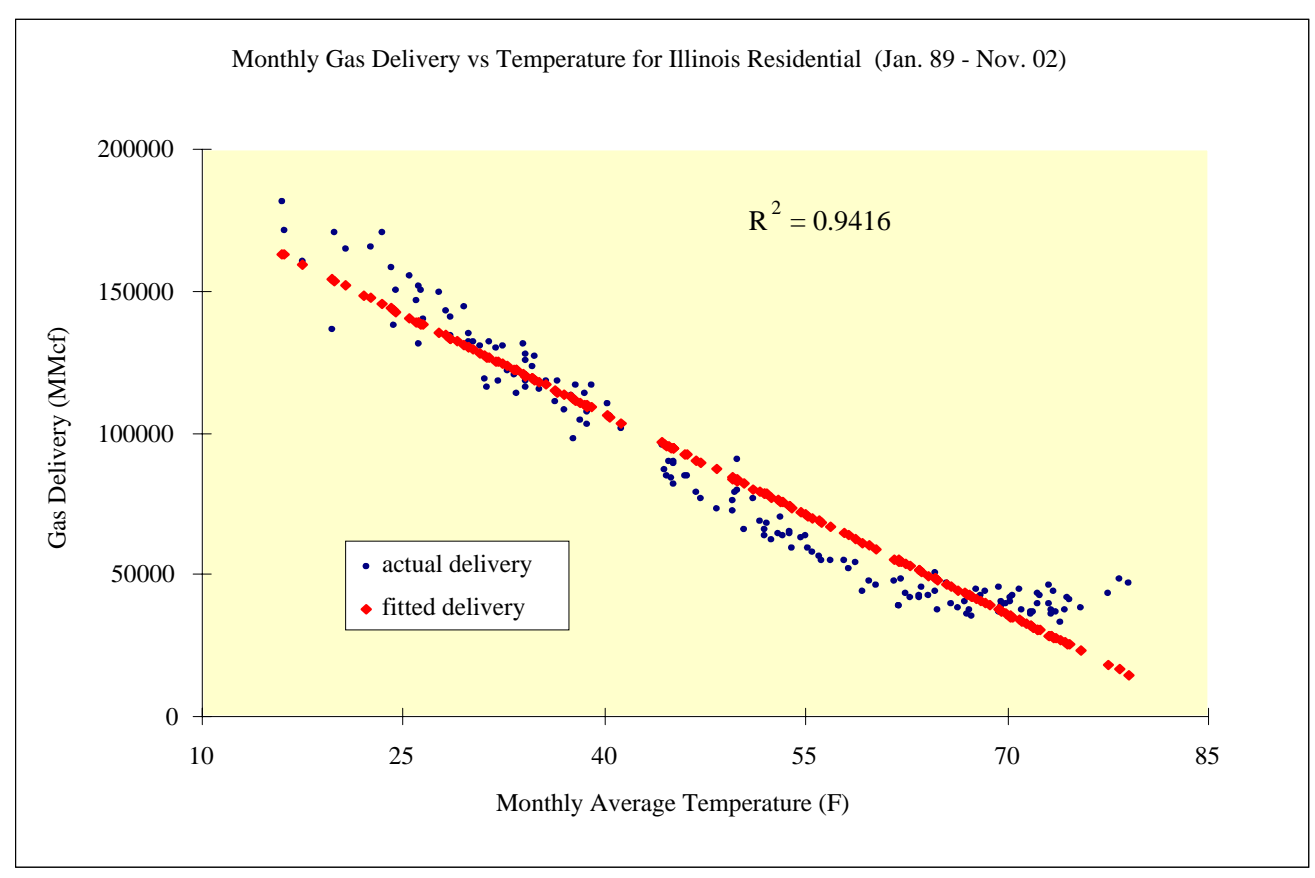


Figure 3: Size of Market by Number of Contract

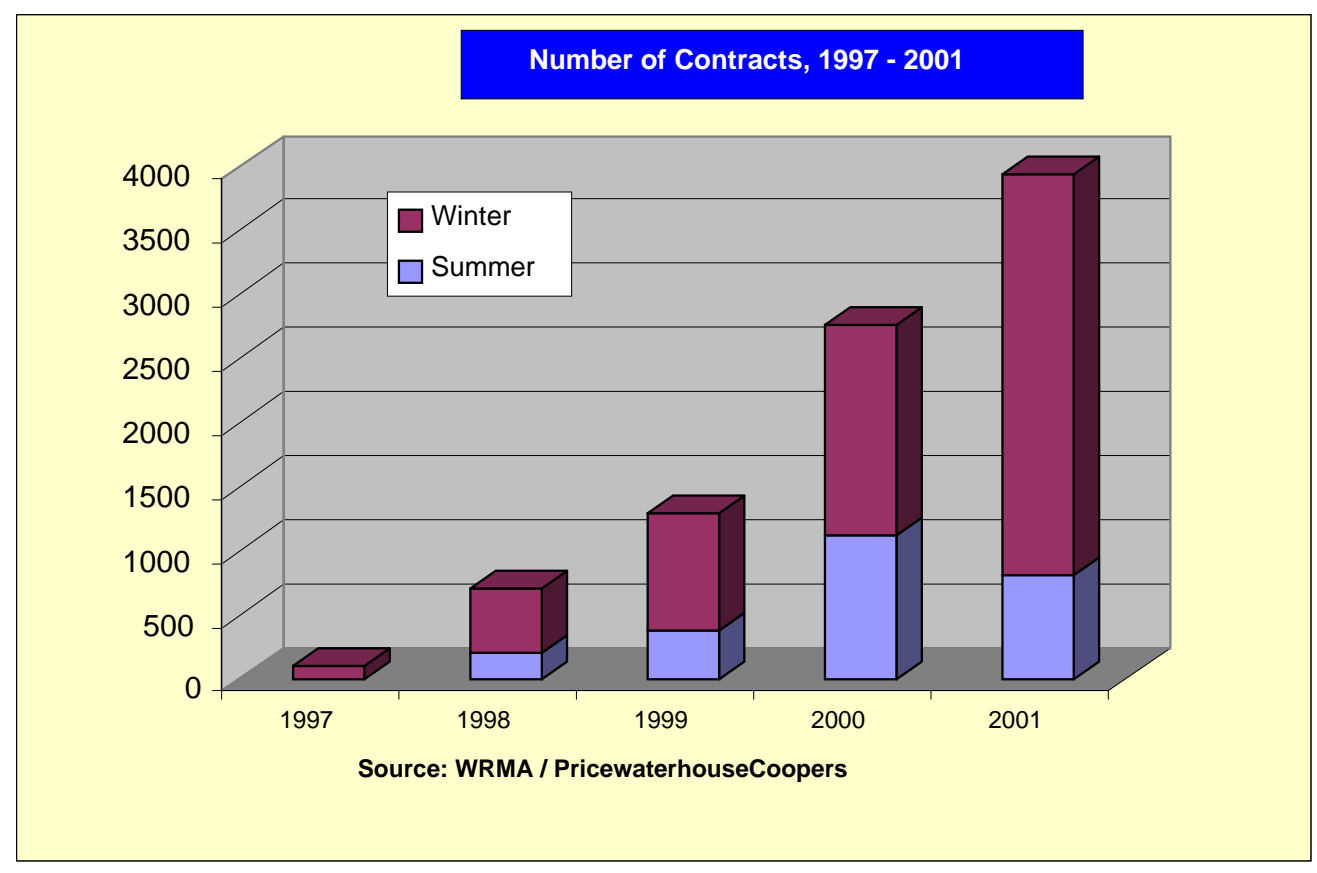

Figure 4: Size of Market by Notional Value

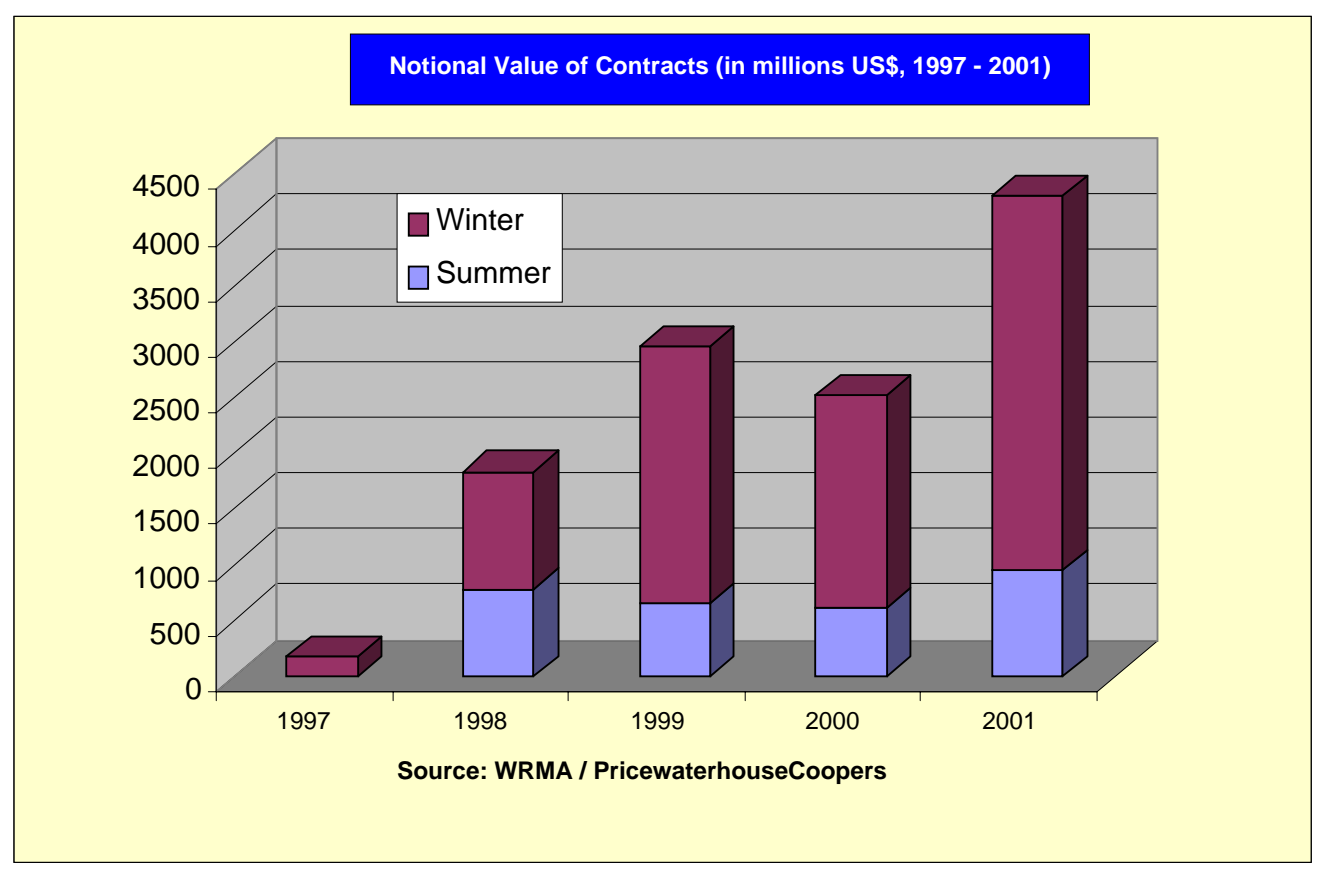


Figure 5: Number of Contracts by Type

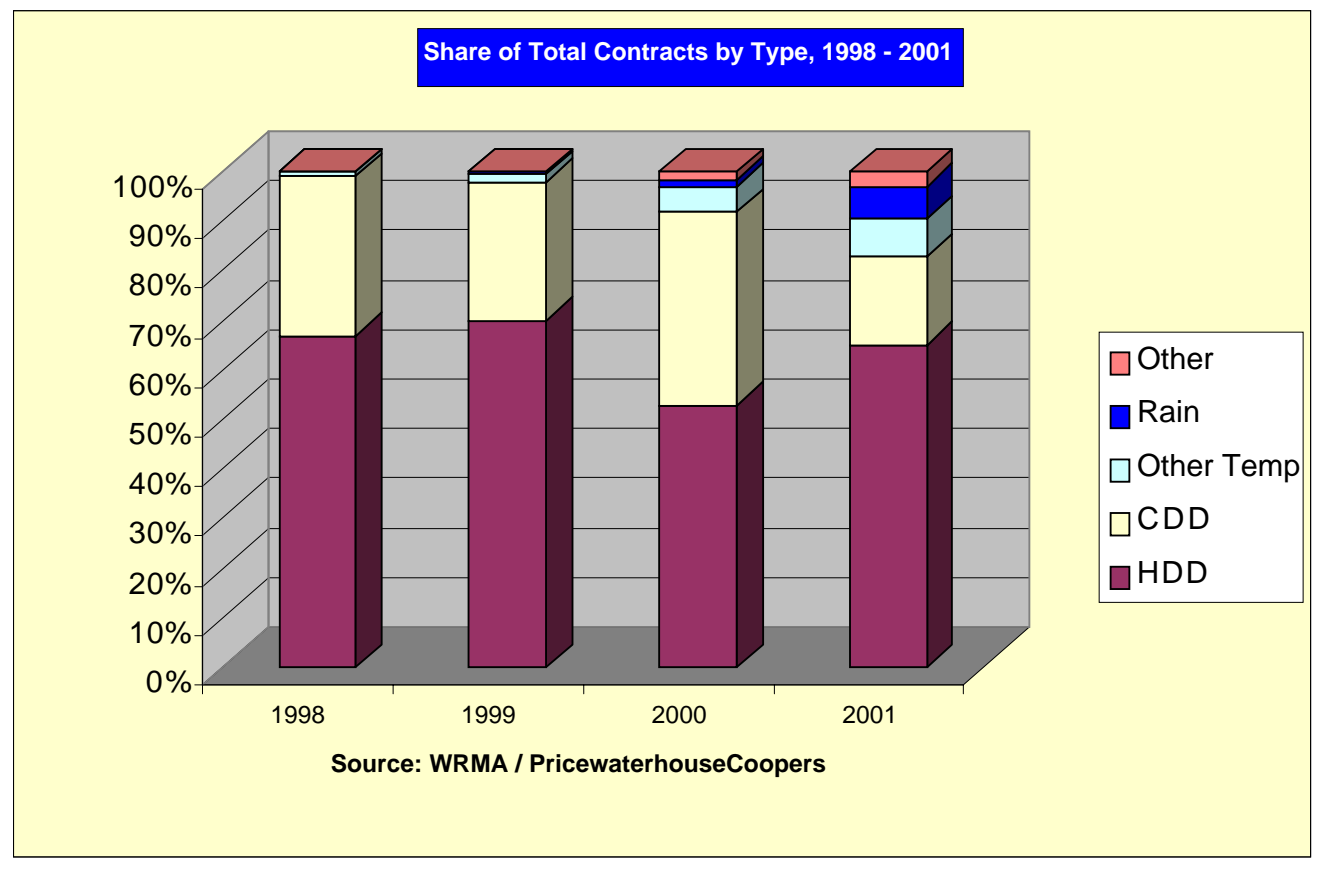

Figure 6: Notional Value by Type

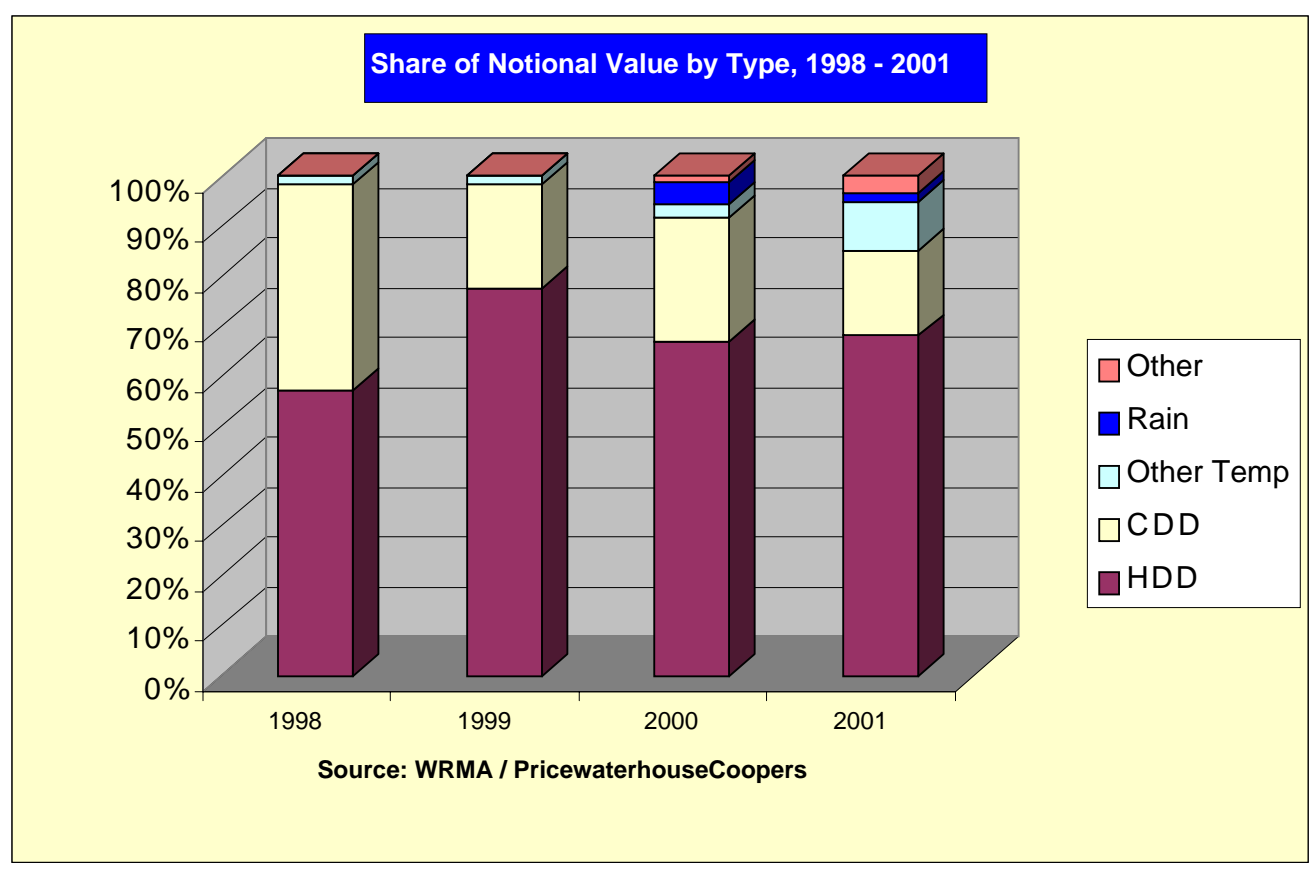


Figure 7: Regional Distribution of Market

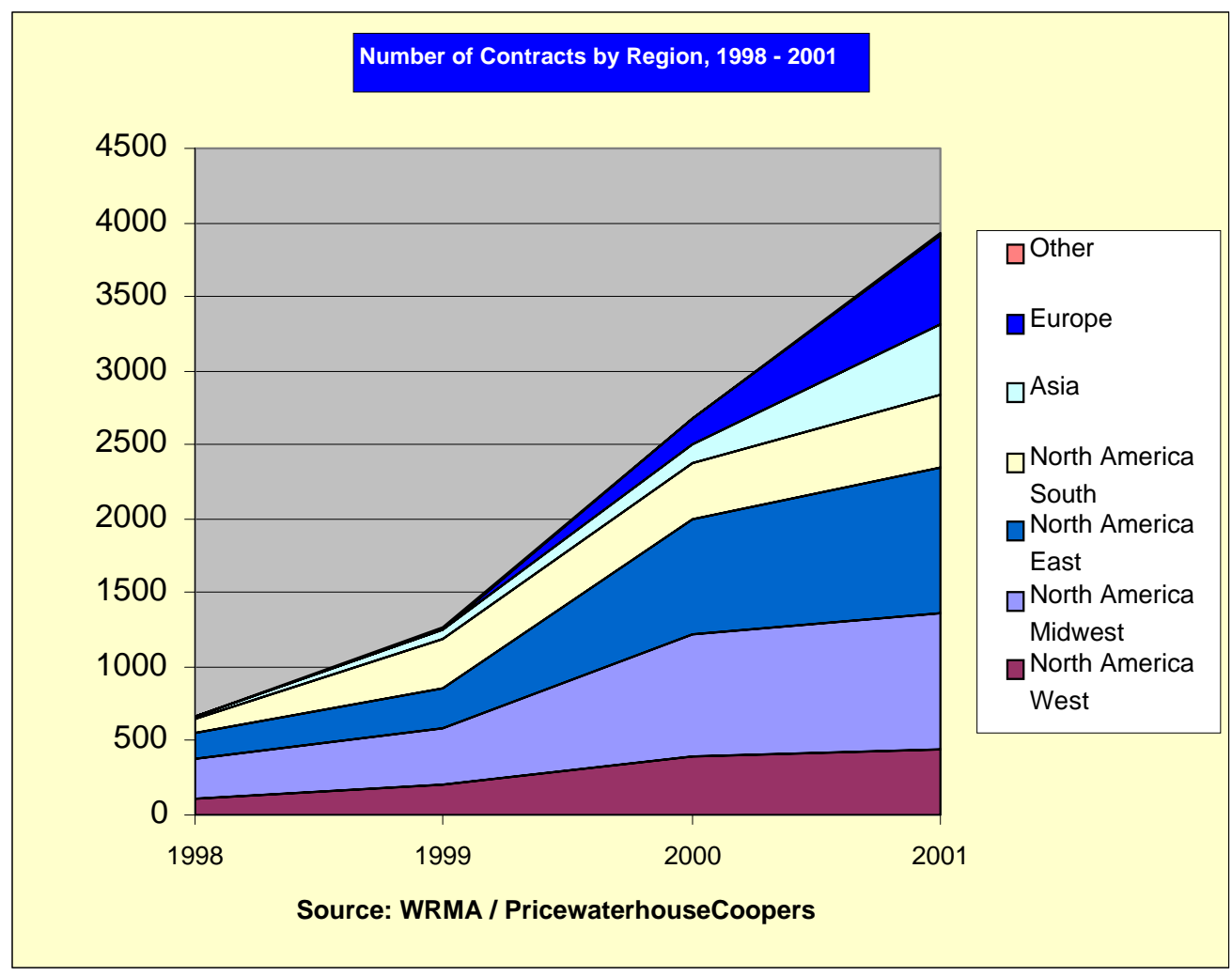




\section{Figure 8: Efficient Frontiers Based on Difffernt Index Sets}

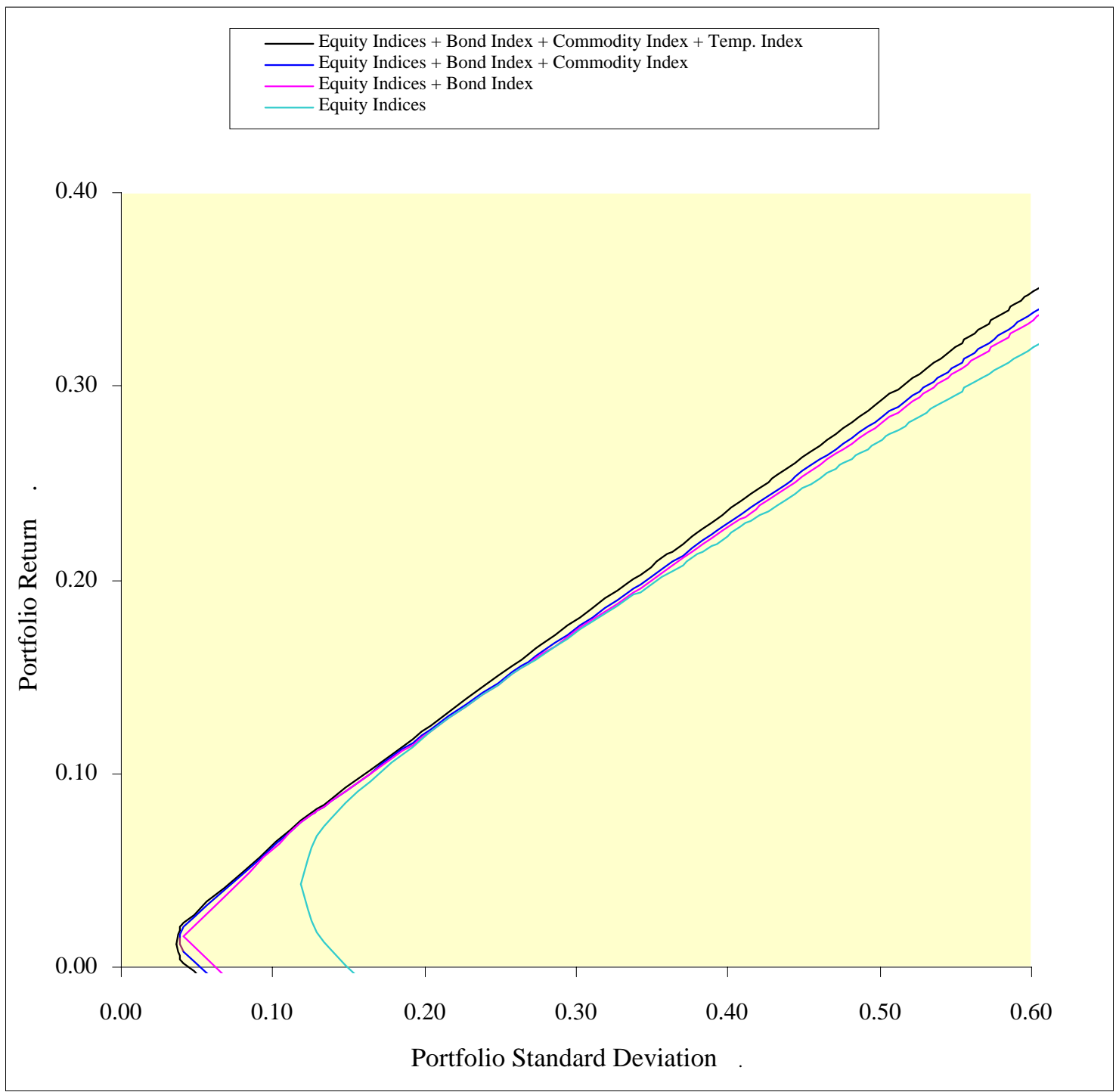

Note: the initial efficient frontier is constructed using the three equity indices only (legend: Equity Indices), and the rest are augmented with one additional index at a time, in the sequence as shown. 
Table 1: HDDs, CDDs and EDDs for June 6 - June 17, 2002 at LaGuardia International Airport,

\begin{tabular}{lcccccccc}
\hline Day & $\begin{array}{c}\text { Daily } \\
\text { Maximum }\end{array}$ & $\begin{array}{c}\text { Daily } \\
\text { Minimum }\end{array}$ & $\begin{array}{c}\text { Daily } \\
\text { Average }\end{array}$ & $\begin{array}{c}\text { Daily } \\
\text { HDDs }\end{array}$ & $\begin{array}{c}\text { Cumulative } \\
\text { HDDs }\end{array}$ & $\begin{array}{c}\text { Daily } \\
\text { CDDs }\end{array}$ & $\begin{array}{c}\text { Cumulative } \\
\text { CDDs }\end{array}$ & $\begin{array}{c}\text { Daily } \\
\text { EDDs }\end{array}$ \\
\hline June 6 & 77 & 59 & 68.0 & 0.0 & 0.0 & 3.0 & 3.0 & 3.0 \\
June 7 & 69 & 57 & 63.0 & 2.0 & 2.0 & 0.0 & 3.0 & 2.0 \\
June 8 & 69 & 55 & 62.0 & 3.0 & 5.0 & 0.0 & 3.0 & 3.0 \\
June 9 & 85 & 57 & 71.0 & 0.0 & 5.0 & 6.0 & 9.0 & 6.0 \\
June 10 & 78 & 65 & 71.5 & 0.0 & 5.0 & 6.5 & 15.5 & 6.5 \\
June 11 & 92 & 64 & 78.0 & 0.0 & 5.0 & 13.0 & 28.5 & 13.0 \\
June 12 & 90 & 60 & 75.0 & 0.0 & 5.0 & 10.0 & 38.5 & 10.0 \\
June 13 & 66 & 57 & 61.5 & 3.5 & 8.5 & 0.0 & 38.5 & 3.5 \\
June 14 & 61 & 56 & 58.5 & 6.5 & 15.0 & 0.0 & 38.5 & 6.5 \\
June 15 & 63 & 55 & 59.0 & 6.0 & 21.0 & 0.0 & 38.5 & 6.0 \\
June 16 & 79 & 61 & 70.0 & 0.0 & 21.0 & 5.0 & 43.5 & 5.0 \\
June 17 & 78 & 63 & 70.5 & 0.0 & 21.0 & 5.5 & 49.0 & 5.5 \\
\hline
\end{tabular}


Table 2: Historical Burn Analysis for HDD Call Options

\begin{tabular}{|c|c|c|c|c|c|c|c|}
\hline \multirow[b]{2}{*}{ Year } & \multicolumn{2}{|c|}{ HDDs } & \multicolumn{2}{|c|}{ Call Option Payoff } & \multirow{2}{*}{$\begin{array}{l}\text { Years in } \\
\text { Average }\end{array}$} & \multicolumn{2}{|c|}{ Call Value Estimate } \\
\hline & Atlanta & New York & Atlanta & New York & & Atlanta & New York \\
\hline 1979 & 1778 & 2841 & 278 & 341 & & & \\
\hline 1980 & 1672 & 2702 & 172 & 202 & & & \\
\hline 1981 & 1698 & 2708 & 198 & 208 & & & \\
\hline 1982 & 1587 & 2791 & 87 & 291 & & & \\
\hline 1983 & 1749 & 2443 & 249 & 0 & & & \\
\hline 1984 & 1660 & 2724 & 160 & 224 & & & \\
\hline 1985 & 1723 & 2567 & 223 & 67 & & & \\
\hline 1986 & 1416 & 2533 & 0 & 33 & & & \\
\hline 1987 & 1602 & 2504 & 102 & 4 & & & \\
\hline 1988 & 1649 & 2593 & 149 & 93 & 10 & 22.50 & 69.60 \\
\hline 1989 & 1242 & 2417 & 0 & 0 & 11 & 34.00 & 71.73 \\
\hline 1990 & 1009 & 2078 & 0 & 0 & 12 & 39.67 & 66.08 \\
\hline 1991 & 1354 & 2217 & 0 & 0 & 13 & 36.62 & 63.54 \\
\hline 1992 & 1325 & 2439 & 0 & 0 & 14 & 49.93 & 63.79 \\
\hline 1993 & 1514 & 2667 & 14 & 167 & 15 & 57.27 & 74.47 \\
\hline 1994 & 1410 & 2921 & 0 & 421 & 16 & 69.25 & 69.81 \\
\hline 1995 & 1295 & 2370 & 0 & 0 & 17 & 70.29 & 82.82 \\
\hline 1996 & 1666 & 2608 & 166 & 108 & 18 & 77.39 & 89.78 \\
\hline 1997 & 1102 & 2377 & 0 & 0 & 19 & 82.37 & 95.68 \\
\hline \multirow[t]{4}{*}{1998} & 1545 & 2060 & 45 & 0 & 20 & 92.15 & 107.95 \\
\hline & & & & & Highest & 92.15 & 107.95 \\
\hline & & & & & Lowest & 22.50 & 63.54 \\
\hline & & & & & Highest / Lowest & 4.10 & 1.70 \\
\hline
\end{tabular}

Note: The HDD call is for the period of January 1 - March 31, 1999. The two columns next to the year column contain the actual realized HDDs for Atlanta and New York. The following two columns contain the payoffs of the calls with exercise prices of 1,500 and 2,500 respectively for Atlanta and New York. The last two columns contain the call option estimates based on different lengths of the sample period. We count the number of years backwards from 1998. For example, a sample of 17 years covers the period of 1982 - 1998, a sample of 16 years covers the period of $1983-1998$, and so on. 
Table 3: Mean, Standard Deviation, Correlation Matrix

\begin{tabular}{|c|c|c|c|c|c|c|c|c|}
\hline & \multicolumn{6}{|c|}{ Correlations } & \multirow[t]{2}{*}{ Mean } & \multirow[t]{2}{*}{ Std } \\
\hline & N. America & Europe & Pacific & Bond & Commodity & Temp. & & \\
\hline N. America & 1.0000 & & & & & & 0.0861 & 0.1612 \\
\hline Europe & 0.3815 & 1.0000 & & & & & 0.0480 & 0.1508 \\
\hline Pacific & 0.1043 & 0.3456 & 1.0000 & & & & -0.0223 & 0.1847 \\
\hline Bond & 0.0014 & -0.0121 & -0.0523 & 1.0000 & & & 0.0126 & 0.0437 \\
\hline Commodity & -0.0103 & -0.0277 & 0.0220 & -0.0755 & 1.0000 & & -0.0027 & 0.1742 \\
\hline Temp. & 0.0192 & -0.0118 & -0.0202 & -0.0078 & -0.0076 & 1.0000 & -0.0002 & 0.0958 \\
\hline
\end{tabular}

Note: there are six index series: equity indices for North America, Europe and Pacific, JP Morgan Bond Index based on U.S. government bonds, Goldman Sachs Commodity Index, and the Temperature Index. The Temperature Index is for New York city, constructed as 1,000 plus the deviation of daily EDDs from the seasonal average EDDs. The sample period is from January 1, 1991 to December 31, 2002 with daily frequency. The mean and standard deviation (Std) for each index are annualized from their daily counterparts. 